\title{
Improved microwave absorption in lightweight resin-based carbon foam by decorating with magnetic and dielectric nanoparticles $\uparrow$
}

\author{
R. Kumar, ${ }^{a}$ A. P. Singh, ${ }^{a}$ M. Chand, ${ }^{b}$ R. P. Pant, ${ }^{b}$ R. K. Kotnala, ${ }^{a}$ S. K. Dhawan, ${ }^{a}$ \\ R. B. Mathur ${ }^{a}$ and S. R. Dhakate*a
}

\begin{abstract}
Carbon foams (CFoams) are sponge-like high performance lightweight engineering materials that possess excellent electrical and mechanical properties as well as thermal stability. CFoams possess bulk density in the range from 0.30 to $0.40 \mathrm{~g} \mathrm{~cm}^{-3}$ and open porosity of more than $70 \%$. The CFoam consists of pore walls, i.e., ligaments, which are responsible for the conduction path and hence the electrical conductivity due to mobile charge carrier (delocalized $\pi$ electron), are interconnected to each other. The high value of electrical conductivity causes the CFoam to act as an electromagnetic radiation reflector rather than an absorber; however, in certain applications, shielding materials must be able to absorb the maximum electromagnetic radiation. Therefore, to improve the absorptivity of electromagnetic radiation in lightweight CFoams, the CFoams are decorated by $\mathrm{Fe}_{3} \mathrm{O}_{4}$ and $\mathrm{ZnO}$ nanoparticles. It is observed that coating with $\mathrm{Fe}_{3} \mathrm{O}_{4}$ and $\mathrm{Fe}_{3} \mathrm{O}_{4}-\mathrm{ZnO}$ nanoparticles not only improved the absorption losses but also enhanced the compressive strength of CFoam by $100 \%$. This modified CFoam demonstrated excellent shielding response in the frequency range from 8.2 to $12.4 \mathrm{GHz}$, in which the total shielding effectiveness (SE) was dominated by absorption losses. The total SE is -45.7 and $-48.5 \mathrm{~dB}$ of $\mathrm{Fe}_{3} \mathrm{O}_{4}$ and $\mathrm{Fe}_{3} \mathrm{O}_{4}-\mathrm{ZnO}$-coated CFoam, respectively, and it is governed by absorption losses of $-34.3 \mathrm{~dB}$ and -41.5 $\mathrm{dB}$, respectively. Moreover, the absorption losses increased by $236 \%$ in $\mathrm{Fe}_{3} \mathrm{O}_{4}$-coated CFoam and $281 \%$ in $\mathrm{Fe}_{3} \mathrm{O}_{4}-\mathrm{ZnO}$-coated CFoam without much enhancement in the bulk density. This is due to the high level of magnetic and dielectric losses of nanoparticles with high surface area. Note that the absorption losses are $80 \%$ higher than any value reported for CFoam; thus, lightweight CFoam decorated with magnetic and dielectric nanoparticles is an excellent material for stealth technology.
\end{abstract}

Received 4th March 2014

Accepted 6th May 2014

DOI: $10.1039 / c 4 r a 01731 e$

www.rsc.org/advances nanoparticles have been explored as EM shielding materials or coatings; however, they have drawbacks of high density, corrosion, difficult/uneconomic processing and low specific shielding capability. ${ }^{3}$ Among different materials for civil and military applications, carbon-based materials have gained popularity because of their high electrical/thermal conductivity, low density, good corrosion resistance, thermal stability and processing advantages. ${ }^{4}$ The properties of carbon materials can be tailored by controlling processing parameters. Carbon-based shielding materials not only protect from EM radiation but also control regulation of thermal heating in electronic power systems to protect them from any form of damage or catastrophe. Therefore, technologists and scientists are looking for highly efficient, thermally conducting and lightweight radar absorbing material (RAM) particularly for aerospace transportation vehicles in civilian, military and space applications. The shielding materials should not only have strong microwave absorption properties but should also be lightweight and costeffective. $^{5}$

Recently, lightweight carbon foam (CFoam) has emerged as a promising candidate for different applications owing to its 
outstanding properties such as low density, large surface area with open cell wall structure, good thermal/electrical transport properties and mechanical stability. ${ }^{6,7}$ The CFoams are spongelike high performance engineering materials, in which carbon ligaments are interconnected to each other, and have recently attracted attention due to their potential applications in various fields. ${ }^{8}$ The CFoam is generally developed from thermosetting and thermoplastic polymers by various techniques. ${ }^{-12}$ The thermosetting polymer, i.e. phenolic resin derived CFoam, is less electrically and thermally conductive, ${ }^{\mathbf{1 3 - 1 5}}$ while coal tar pitch and mesophase pitch derived CFoams are thermally and electrically conductive. ${ }^{16,17}$ In both the cases, EM shielding effectiveness (SE) is dominated by reflection losses rather than absorption losses due to the high electrical conductivity value of CFoam. ${ }^{18,19}$

In the literature, a few studies on CFoam are available, in which CFoam is heat-treated in temperatures ranging from 400 to $800{ }^{\circ} \mathrm{C}^{20-27}$ Yang et al. ${ }^{20}$ reported the development of CFoam from mesophase pitch by foaming technique and studied its microwave (2-18 GHz) absorption characteristics. It is found that CFoam heat-treated at 600 and $700{ }^{\circ} \mathrm{C}$ exhibits better microwave absorption (reflection loss $10 \mathrm{~dB}$ ). Fang et $a .^{22}$ reported electromagnetic characteristics of CFoams with different pore size and electrical conductivities, which are controlled by carbonization temperature $\left(700-760{ }^{\circ} \mathrm{C}\right)$. The electromagnetic parameters of these CFoams and their corresponding pulverized powders are measured by a resonant cavity perturbation technique at a frequency of $2.45 \mathrm{GHz}$. Note that CFoam has a dielectric loss that is several times larger than their corresponding pulverized powder. Recently, Moglie et al. ${ }^{23}$ studied the EM SE of CFoam (GRAFOAM FPA-20 and FRA-10) in the frequency band of 1-4 GHz using the nested reverberation chamber method. It has been reported that total SE increases with increasing thickness of CFoam. Micheli et al. ${ }^{24}$ reported the effect of a multi-walled carbon nanotube epoxy resin mixture filled in the pores of CFoam, and studied its role on EM radiation absorption properties of CFoam in the frequency range 2-3 GHz. It is found that reflection coefficient reaches up to $-45 \mathrm{~dB}$. Blacker et $a .^{25}$ reported EM SE (40 dB) in the frequency range of $400 \mathrm{MHz}$ to $18 \mathrm{GHz}$ of rigid porous electrically conductive CFoam, in which electrically conductive carbon nanofiber polymer matrix is used for joining the CFoam enclosures. Blacker et $a l^{\mathbf{2 6}}$ reported the development of an electrically graded CFoam material whose electrical resistivity increases with increasing the thickness and decreases with increasing processing temperature. These electrically graded CFoams can be used as radar absorbers. Kuzhir et al. ${ }^{27}$ reported the EM SE of CFoam developed from commercial tannin and furfuryl alcohol, which is pyrolysed at $900{ }^{\circ} \mathrm{C}$. The absorption and reflection of EM SE in microwaves depends on the density of the CFoam. The maximal SE value is $23 \mathrm{~dB}$ in $\mathrm{K}_{\alpha}$ band (26-40 $\mathrm{GHz})$ achieved for the density $\left(0.150 \mathrm{~g} \mathrm{~cm}^{-3}\right)$ of CFoam.

The microwave absorption of shield material is due to the different interactive energy dissipation processes of polarization and magnetization. ${ }^{28}$ Therefore, in the present study, to improve the microwave absorption, CFoams derived from phenolic resin are coated with magnetic ferrofluid and dielectric zinc oxide nanoparticles. The resultant CFoams are characterized by scanning electron microscopy, transmission electron microscopy, Raman spectroscopy, X-ray diffraction, vibration sample magnetometer and vector network analyzer.

\section{Experimental section}

\subsection{Development of carbon foam}

Thermosetting phenolic resin-based CFoams were prepared by sacrificial template route by impregnating phenolic resin into the commercially available polyurethane (PU) foams. The PU foam used as template possesses density $0.030 \mathrm{~g} \mathrm{~cm}^{-3}$ and average pore size $0.45 \mathrm{~mm}$. The solution of phenolic resin (40 wt\%) and organic solvent was prepared to impregnate the PU foam. The porous PU foam slabs were cleaned with acetone and dried for 15 minutes followed by drying in a hot oven for $2 \mathrm{~h}$, and the dried foams were impregnated with the resin solution at room temperature. The impregnation was carried out carefully by removing excess resin solution in order to avoid retention of resin into the pores of the substrate foam resulting in a uniform structure in the final product. Then, impregnated foams were dried at $60{ }^{\circ} \mathrm{C}$ for $12 \mathrm{~h}$, and the dried resin impregnated foams were cured at $150{ }^{\circ} \mathrm{C}$ in the presence of air atmosphere for $12 \mathrm{~h}$ for increasing the cross-linking between the polymeric chains. These cured foam slabs were pyrolysed at $500{ }^{\circ} \mathrm{C}$ for $1 \mathrm{~h}$ and later carbonized at $1000{ }^{\circ} \mathrm{C}$ in inert atmosphere to obtain the CFoam. The resulting carbonized foam was denoted as CFoam C1.

The CFoam $\mathrm{C} 1$ was coated with magnetic $\left(\mathrm{Fe}_{3} \mathrm{O}_{4}\right)$ and dielectric $\mathrm{ZnO}$ nanoparticles to improve the radar emission absorptivity, i.e. EM radiation can be absorbed by material. In the first case, CFoam C1 was coated with ferrofluid solution using dip coating and the resultant product is denoted as CFoam C2. Note that the ferrofluid was a colloidal suspension of $\mathrm{Fe}_{3} \mathrm{O}_{4}$ nanoparticles. In another case, CFoam $\mathrm{C} 1$ was coated with ferrofluid and $\mathrm{ZnO}$ nanoparticles and the resultant product is denoted as CFoam C3. The ZnO nanoparticles were prepared by thermal evaporation of zinc acetate ${ }^{29}$ at $60-70{ }^{\circ} \mathrm{C}$ with slow heating. After coating with nanoparticles, these CFoams were heat-treated at $650{ }^{\circ} \mathrm{C}$ for 10 minutes in an inert atmosphere. Moreover, in the case of CFoam C2, loading of the $\mathrm{Fe}_{3} \mathrm{O}_{4}$ nanoparticles was $14 \mathrm{wt} \%$, whereas in the case of CFoam $\mathrm{C} 3, \mathrm{Fe}_{3} \mathrm{O}_{4}$ and $\mathrm{ZnO}$ loading was $7 \mathrm{wt} \%$ each with respect to weight of CFoam. These CFoams were characterized by different techniques for evaluation of radar emission absorptivity.

\subsection{Characterization}

Raman spectra of the CFoam samples were recorded using Renishaw inVia Raman spectrometer, UK, with laser as an excitation source at $514 \mathrm{~nm}$. The crystal structure of the CFoam samples was studied by X-ray diffraction (XRD, D-8 Advanced Bruker diffractometer) using $\mathrm{CuK}_{\alpha}$ radiation $(\lambda=1.5418 \AA)$. The surface morphology of the CFoam samples was observed by a scanning electron microscope (SEM, VP-EVO, MA-10, Carl-Zeiss, UK) operating at an accelerating potential of $10.0 \mathrm{kV}$. The electrical conductivity CFoam (size $60 \mathrm{~mm} \times 20 \mathrm{~mm} \times 4 \mathrm{~mm}$ ) 
was measured by DC four probe contact method using a Keithley 224 programmable current source for providing current. The voltage drop was measured by Keithley 197A auto ranging digital microvoltmeter. The values reported in the text are an average of six readings of voltage drops at different portions of the sample. EM-SE and EM attributes (complex permittivity and permeability) were measured by waveguide using vector network analyzer (VNA E8263B Agilent Technologies). The rectangular samples of thickness $2.75 \mathrm{~mm}$ were placed inside the cavity of the sample holder, which matches the internal dimensions of the X-band (8.4-12.4 GHz) wave guide. The sample holder was placed between the flanges of the waveguide connected between the two ports of the VNA. The magnetic property of the CFoam samples was measured by vibration sample magnetometer (VSM) model 7304 (Lakeshore Cryotronics Inc., USA) with a maximum magnetic field of 1.2 T, using a Perspex holder vibrating horizontally at frequency of $76 \mathrm{~Hz}$.

\section{Results and discussion}

\subsection{Electrical conductivity of CFoams}

The CFoam C1 developed by sacrificial template technique from thermosetting phenolic resin possesses bulk density of $0.34 \mathrm{~g}$ $\mathrm{cm}^{-3}$. The coating of $\mathrm{Fe}_{3} \mathrm{O}_{4}$ particles on CFoam, increases the bulk density of CFoam $\mathrm{C} 2$ from $0.34 \mathrm{~g} \mathrm{~cm}^{-3}$ to $0.40 \mathrm{~g} \mathrm{~cm}^{-3}$. Furthermore, the density of CFoam $\mathrm{C} 1$ coated with a mixture of $\mathrm{Fe}_{3} \mathrm{O}_{4}-\mathrm{ZnO}$ nanoparticles (CFoam C3) is almost the same as CFoam C2. The attenuation of microwaves depends upon the electric and magnetic properties of the CFoam; therefore, electrical conductivity of all the CFoam was measured, and it is listed in Table 1. The electrical conductivity of CFoam C1 is $20 \mathrm{~S} \mathrm{~cm} \mathrm{~cm}^{-1}$ because foam derived from the phenolic resin possesses higher conductivity due to the delocalized $\pi$ electron in the carbon network, but the electrical conductivity is comparatively very less compared to pitch-based carbon foam. ${ }^{30}$ However, $\mathrm{Fe}_{3} \mathrm{O}_{4}$-coated CFoam C2 electrical conductivity decreases to $13 \mathrm{~S}$ $\mathrm{cm}^{-1}$. Furthermore, on mix coating of $\mathrm{Fe}_{3} \mathrm{O}_{4}-\mathrm{ZnO}$ (CFoam C3), the electrical conductivity is almost the same as CFoam C2. The decrease in conductivity is due to the $\mathrm{Fe}_{3} \mathrm{O}_{4}$ and $\mathrm{ZnO}$ inhibiting the conduction path of the electrons. The interactions between conducting CFoam and $\mathrm{Fe}_{3} \mathrm{O}_{4}-\mathrm{ZnO}$ particles during heat treatment at temperature $650{ }^{\circ} \mathrm{C}$ form a complex, which can reduce the conductivity; moreover, the coating of magnetic and dielectric nanoparticles on the surface of the CFoam increases the contact resistance, which can inhibit the conduction path.

The $\mathrm{Fe}_{3} \mathrm{O}_{4}$ and $\mathrm{ZnO}$ nanoparticle coating on the CFoam have a positive effect on the mechanical properties. Strength is one of the essential requirements of CFoams because compressive forces are often encountered during their use in real application. Therefore, the compressive strength of CFoam should be sufficient to avoid any form of structural damage. The compressive strength of CFoam depends mainly on two factors, namely, microstructure and bulk density. It is observed that the compressive strength of CFoam $\mathrm{C} 1, \mathrm{Fe}_{3} \mathrm{O}_{4}$-coated CFoam C2 and $\mathrm{Fe}_{3} \mathrm{O}_{4}-\mathrm{ZnO}$-coated CFoam $\mathrm{C} 3$ is $4.0 \mathrm{MPa}, 7 \mathrm{MPa}$ and $8 \mathrm{MPa}$, respectively. This enhancement in strength is related to the increase in bulk density and decrease in stress concentration centre as the coating might reduce the number of cracks in the CFoam. In the shield, material heat is generated due to the absorption of EM radiation; therefore, the CFoam should have sufficient thermal conductivity for heat dissipation. The thermal conductivity of CFoam is measured by laser flash method, and it is found to be $0.54 \mathrm{~W} \mathrm{~m}^{-1} \mathrm{~K}^{-1}$.

\subsection{Morphology of CFoam}

Fig. 1 depicts the SEM micrographs of the PU template foam, CFoam C1, C2 and C3. The PU template foam possesses different size and shapes of cells (Fig. 1a), which are connected

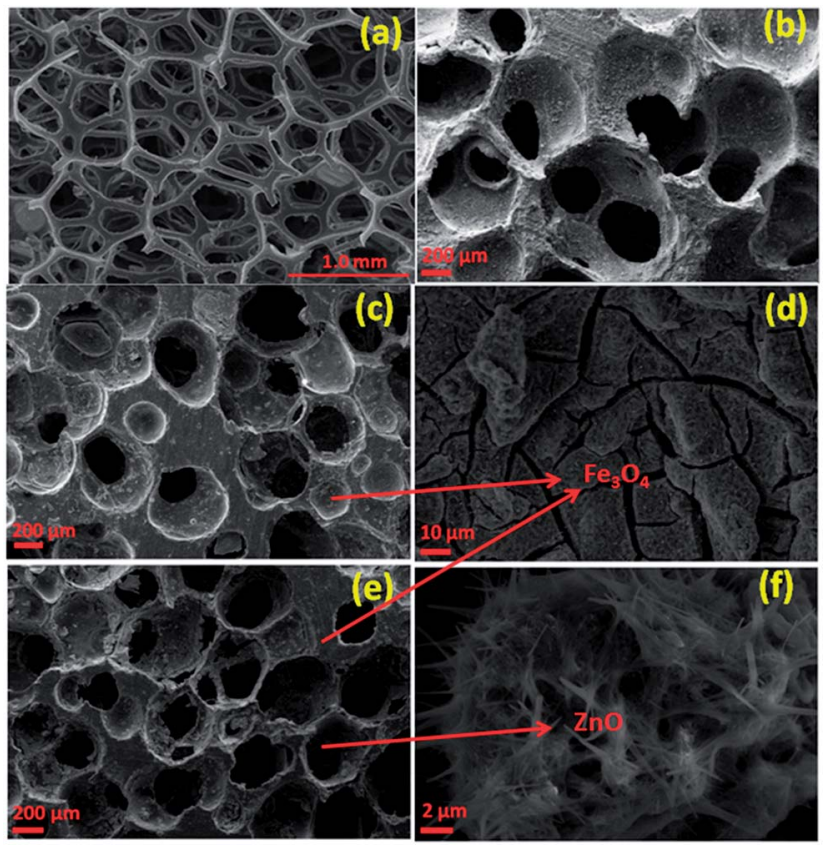

Fig. 1 SEM images of (a) polyurethane template foam, (b) CFoam C1, (c) CFoam C2 coated with $\mathrm{Fe}_{3} \mathrm{O}_{4}$, (d) CFoam C2, in which cracks were generated after heating, (e) CFoam $\mathrm{C} 3$ coated with $\mathrm{Fe}_{3} \mathrm{O}_{4}-\mathrm{ZnO}$, (f) $\mathrm{ZnO}$ nanorods generated inside the pores of CFoam C3.

Table 1 Properties of carbon foam

\begin{tabular}{lllll}
\hline CFoam & $\begin{array}{l}\text { Bulk density } \\
\left(\mathrm{g} \mathrm{cm}^{-3}\right)\end{array}$ & $\begin{array}{l}\text { Electrical conductivity } \\
\left(\mathrm{S} \mathrm{cm}^{-1}\right)\end{array}$ & $\begin{array}{l}\text { Thermal conductivity } \\
\left(\mathrm{W} \mathrm{m}^{-1} \mathrm{~K}^{-1}\right)\end{array}$ & $\begin{array}{l}\text { Compressive strength } \\
(\mathrm{MPa})\end{array}$ \\
\hline $\mathrm{C} 1$ & 0.34 & 20.00 & 0.54 & 4.00 \\
$\mathrm{C} 2$ & 0.40 & 14.00 & - & 7.00 \\
C3 & 0.40 & 13.50 & - & 8.00
\end{tabular}


by thin walls. In CFoam C1, the cells are of different sizes and the distribution of cells is not uniform (Fig. 1b). In CFoam C1, cells are mainly open with incomplete cell membranes and each cell is partly sealed off from its neighboring cell, i.e., ligaments. In $\mathrm{Fe}_{3} \mathrm{O}_{4}$-coated CFoam C2 (Fig. 1c), stress is exerted on the cell membranes during heat treatment at $650{ }^{\circ} \mathrm{C}$ and as a results the cells are open; however, cracks developed in the $\mathrm{Fe}_{3} \mathrm{O}_{4}$-coated ligaments (Fig. 1d, magnified view of cell wall) due to the differential thermal expansion of CFoam and $\mathrm{Fe}_{3} \mathrm{O}_{4}$ nanoparticles. The ferrofluid consists of $\mathrm{Fe}_{3} \mathrm{O}_{4}$ nanoparticles of size ranging from $50-100 \mathrm{~nm}$, and after coating on the CFoam it will get agglomerated (ESI, Fig. S1a and $\mathrm{b} \dagger$ ). Moreover, as depicted in Fig. 1d, cracks developed on the surface of CFoam in the coating area which are maximum on the pore walls or ligaments (ESI, Fig. S1c $\dagger$ ). Fig. 1e shows SEM image of CFoam C3 coated with $\mathrm{Fe}_{3} \mathrm{O}_{4}-\mathrm{ZnO}$ nanoparticles. As observed in CFoam $\mathrm{C} 2$ (Fig. 1c), the $\mathrm{Fe}_{3} \mathrm{O}_{4}$ particles are coated on the surface of the ligaments of CFoam; however, in the case of CFoam C3, $\mathrm{Fe}_{3} \mathrm{O}_{4}$ is coated on the ligaments and $\mathrm{ZnO}$ nanoparticles impregnated inside the pores.

The evolution of in situ $\mathrm{ZnO}$ nanorods in the pores after heat treatment of CFoam at $650{ }^{\circ} \mathrm{C}$ is shown in Fig. 1 (e and $\mathrm{f}$ ). The ZnO nanoparticles were synthesized by thermal evaporation of zinc acetate at low temperature $\left(60-70{ }^{\circ} \mathrm{C}\right)$ and the morphology of the $\mathrm{ZnO}$ nanoparticles is shown in the ESI (Fig. S2a $\dagger$ ). The $\mathrm{ZnO}$ nanoparticles with ferrofluid solution were coated on the CFoam and heat-treated at $650{ }^{\circ} \mathrm{C}$. $\mathrm{Fe}_{3} \mathrm{O}_{4}$ was mostly coated on the surface of the CFoam, while some $\mathrm{Fe}_{3} \mathrm{O}_{4}$ nanoparticles and $\mathrm{ZnO}$ impregnated mostly into the pores of the CFoam. After heat treatment, a flower-type morphology of $\mathrm{ZnO}$ and $\mathrm{Fe}_{3} \mathrm{O}_{4}$ is observed inside the pores, which is shown in the ESI (Fig. S2b-d †). From the transmission electron microscopy (TEM) image of $\mathrm{ZnO}$ nanoparticles, it is observed that $\mathrm{ZnO}$ nanoparticles have an average diameter of $70 \mathrm{~nm}$. At higher magnification, a fringe type structure is repeatedly observed in the nanorods, which is evidence of the fact that during heat treatment $\mathrm{ZnO}$ particles transform into a nanorod-like structure (Fig. 1f).

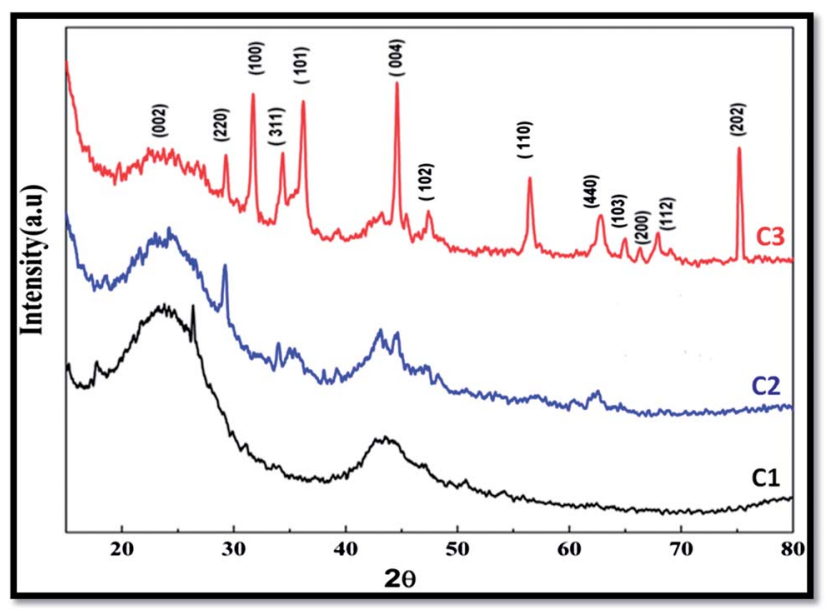

Fig. 2 X-ray diffraction patterns of CFoams C1, C2 and C3.

\subsection{X-ray diffraction and Raman spectra of CFoams}

Fig. 2 shows the XRD pattern of CFoams C1, C2 and C3. The CFoam $\mathrm{C} 1$ is carbon derived from the phenolic resin and consists of two peaks at $2 \theta$ equal to $24.1^{\circ}$ and $44.4^{\circ}$, corresponding to the amorphous carbon of 002 and 101 lattice planes. The CFoam C2 is $\mathrm{Fe}_{3} \mathrm{O}_{4}$-coated and consists of peaks of amorphous carbon and $\mathrm{Fe}_{3} \mathrm{O}_{4}$ at $2 \theta$ equal to $29.18^{\circ}, 35.1^{\circ}$, $43.26^{\circ}, 44.6^{\circ}, 57.15^{\circ}$ and $62.55^{\circ}$. The XRD pattern of magnetic nanoparticles $\left(\mathrm{Fe}_{3} \mathrm{O}_{4}\right)$ is given in the ESI (Fig. $\mathrm{S} 4 \dagger$ ). During the heat treatment, interactions between the carbon and $\mathrm{Fe}_{3} \mathrm{O}_{4}$ nanoparticles occur at temperatures ranging from 500 to $650{ }^{\circ} \mathrm{C}$, which form $\mathrm{Fe}-\mathrm{C}$. It is well known that carbon is a reducing agent that can react with $\mathrm{Fe}-\mathrm{O}$ compounds during heat treatment and these compounds can transform into iron carbide. ${ }^{31}$ Moreover, the peaks of $\mathrm{Fe}_{3} \mathrm{O}_{4}$ are shifted to a lower diffraction angle, which suggests successful incorporation of the dopant in the host matrix.

In case of CFoam C3, it is observed that $\mathrm{ZnO}$ and $\mathrm{Fe}_{3} \mathrm{O}_{4}$ coexist with carbon, which results in a change in the peak position and has a positive effect on the magnetic properties of the CFoams. Therefore, CFoam C3 consists of peaks for amorphous carbon, $\mathrm{Fe}_{3} \mathrm{O}_{4}$ and $\mathrm{ZnO}$ at $2 \theta$ equal to $24.70^{\circ}, 29.26^{\circ}$, $31.66^{\circ}, 34.46^{\circ}, 36.22^{\circ}, 44.626^{\circ}, 47.42^{\circ}, 56.43^{\circ}, 62.876^{\circ}, 64.95^{\circ}$, $67.958^{\circ}$ and $75.32^{\circ}$. In Fig. S4, $\dagger$ the X-diffraction pattern of $\mathrm{ZnO}$ is given ( $\left.\mathrm{ESI}^{\dagger}\right)$. The spectrum consist of peaks at $2 \theta$ equal to $31.8^{\circ}, 34.5^{\circ}, 36.4^{\circ}, 47.6^{\circ}, 56.4^{\circ}, 62.9^{\circ}$, and $68.0^{\circ}$, corresponding to the $100,002,101,102,110,103$, and 200 lattice planes of the wurtzite $\mathrm{ZnO}$ structure. $^{32}$

Fig. 3a shows the Raman spectra of CFoams C1, C2 and C3 in the Raman shift range of $1000-3000 \mathrm{~cm}^{-1}$. Raman spectra illustrate common features in the Raman shift 1000-3000 $\mathrm{cm}^{-1}$ region with the $\mathrm{G}, \mathrm{D}$ and $2 \mathrm{D}$ band observed at around 1560 , 1360 and $2700 \mathrm{~cm}^{-1}$, respectively. The $\mathrm{G}$ band corresponds to the $\mathrm{E}_{2 \mathrm{~g}}$ phonon at the Brillion zone centre. The $\mathrm{D}$ band is due to the breathing modes of the $\mathrm{sp}^{2}$ atoms and requires a defect for its activation, and it only gives information about the amount of disorder in the given structure. ${ }^{33,34}$ In this investigation, the CFoam is derived from a phenolic resin, which is heat-treated at $1000{ }^{\circ} \mathrm{C}$, and it gives hard carbon, which is amorphous in nature. The spectrum of CFoam C1 consists of D and $\mathrm{G}$ band peaks at 1349 and $1597 \mathrm{~cm}^{-1}$ while in the case of CFoam C2 and C3 peaks appear at almost the same Raman shift (1348 and 1601 $\mathrm{cm}^{-1}$ ) but the intensity is different. The intensity ratio of the $\mathrm{D}$

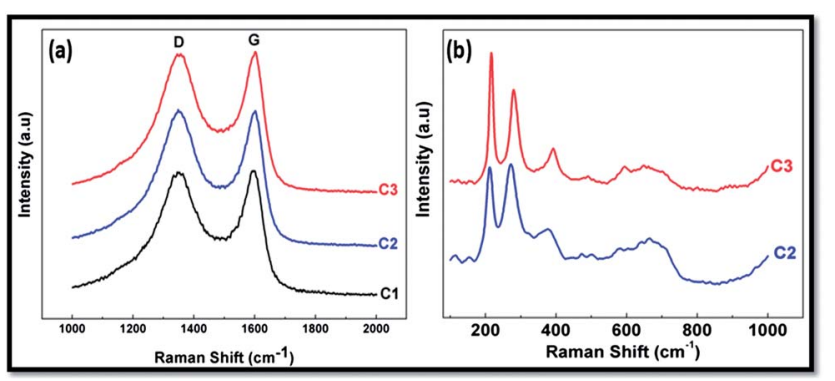

Fig. 3 (a) Raman spectra of CFoams C1, C2 and C3. (b) Raman spectra of CFoams C2 and C3 in the Raman shift range $\left(100-900 \mathrm{~cm}^{-1}\right)$. 
and $\mathrm{G}\left(I_{\mathrm{D}} / I_{\mathrm{G}}\right)$ peaks gives an idea of the defect level in the structure of the CFoam, i.e. $\mathrm{sp}^{3}$-bonded carbon. The higher the $I_{\mathrm{D}} / I_{\mathrm{G}}$ ratio of CFoam, the lower the amount of $\mathrm{sp}^{2}$-bonded carbon, i.e. more defects in the structure.

The CFoam C1 has an $I_{\mathrm{D}} / I_{\mathrm{G}}$ ratio of 0.955 while in the case of $\mathrm{C} 2$ and $\mathrm{C} 3$ it increases to 1.03. This demonstrates that the $\mathrm{Fe}_{3} \mathrm{O}_{4}$ and $\mathrm{ZnO}$ coating form a complex with the $\mathrm{sp}^{3}$ carbon and a consequence increase the $I_{\mathrm{D}} / I_{\mathrm{G}}$ ratio and decrease the electrical conductivity of $\mathrm{C} 2$ and $\mathrm{C} 3$. The decreases in electrical conductivity due to the increases in defect level in the CFoam can influence the shielding effectiveness of the CFoams C2 and C3. As a result, the absorption component increases and the reflection component of total SE decreases in CFoams C2 and C3. Hence, total SE increases due to the higher contribution of the absorption component. The Raman spectra in the range of $200-1000 \mathrm{~cm}^{-1}$ of CFoam are depicted in Fig. $3 \mathrm{~b}$; in this region, the peak appears to be related to the $\mathrm{Fe}_{3} \mathrm{O}_{4}$ and $\mathrm{ZnO}$ nanoparticles. In the case of $\mathrm{Fe}_{3} \mathrm{O}_{4}$-coated CFoam $\mathrm{C} 2$ peaks observed at Raman shift of $215,280,380,422,496$ and $663 \mathrm{~cm}^{-1}$ and the peak between 710 and $720 \mathrm{~cm}^{-1}$ is clear evidence of the magnetite nanocrystals $\left(\mathrm{Fe}_{3} \mathrm{O}_{4}\right)$ with the surface partially oxidized to maghemite. ${ }^{29,35}$ However, in the case of the $\mathrm{Fe}_{3} \mathrm{O}_{4}$ and $\mathrm{ZnO}$-coated CFoam C3, peaks $\sim 340,442$, and $580 \mathrm{~cm}$ are attributable to the $\mathrm{ZnO}$ nanoparticles, in addition to the peaks for $\mathrm{Fe}_{3} \mathrm{O}_{4}$. Raman active zone-center optical phonons predicted by the group theory are $A_{1}+E_{1}+2 E_{2}$. The phonons of $A_{1}$ and $E_{1}$ symmetry are polar phonons; hence, they exhibit different frequencies for the transverse-optical (TO) and longitudinaloptical (LO) phonons. Nonpolar phonon modes with symmetry $\mathrm{E}_{2}$ have two frequencies. $\mathrm{E}_{2} \mathrm{H}$ is associated with oxygen atoms and $\mathrm{E}_{2} \mathrm{~L}$ is associated with the $\mathrm{Zn}$ sub lattice. The presence of a sharp $\mathrm{E}_{2} \mathrm{H}\left(442 \mathrm{~cm}^{-1}\right)$ mode with high intensity and the secondorder Raman mode at $340 \mathrm{~cm}^{-1}$ in the Raman spectra indicates that the obtained sample possesses wurtzite ZnO. According to the theory of polar optical phonons, the wave number of LO phonon mode in $\mathrm{ZnO}$ should be between 574 and $591 \mathrm{~cm}^{-1}$ for wurtzite nanocrystals.

\subsection{Permittivity and magnetic permeability of CFoam}

Fig. 4 shows the EM attributes, relative complex permittivity $\left(\varepsilon^{*}=\varepsilon^{\prime}-i \varepsilon^{\prime \prime}\right)$ and relative complex permeability $\left(\mu^{*}=\mu^{\prime}-i \mu^{\prime \prime}\right)$ of CFoam measured in the frequency region $8.2-12.4 \mathrm{GHz}$ to correlate with the microwave shielding properties of CFoams. These complex parameters have been estimated from experimental scattering parameters $\left(S_{11} \& S_{21}\right)$ by standard NicholsonRoss and Weir theoretical calculation. ${ }^{36,37}$ The estimated real part of the EM parameters $\left(\varepsilon^{\prime}, \mu^{\prime}\right)$ is directly associated with the amount of polarization occurring in the material, which represents the storage ability of the electric and magnetic energy, while the imaginary part $\left(\varepsilon^{\prime \prime}, \mu^{\prime \prime}\right)$ signifies the dissipated electric and magnetic energy. Fig. $4 \mathrm{a}$ and $\mathrm{b}$ clearly demonstrate that both the real and the imaginary part of the permittivity $\left(\varepsilon^{\prime}, \varepsilon^{\prime \prime}\right)$ vary with frequency in all the CFoams. The real permittivity in CFoams C2 and C3 decreases with increasing frequency while CFoam C1 exhibits a broad peak in the frequency region 9.510.5 GHz, which reveals the resonance behaviour due to the high electrical conductivity (Fig. 4a). Furthermore, skin effect becomes significant ${ }^{38}$ in CFoam due to its high surface area and high conductivity. The decreasing permittivity in C2 and C3 with frequency could be ascribed to the decreasing capability of the dipoles to sustain the in-phase movement with the speedily pulsating electric vector of the incident radiation. The real permittivity at fixed frequency of $10 \mathrm{GHz}$ is 90,40 and 15 for CFoams C1, C2 and C3, respectively.

According to EM theory, ${ }^{39,40}$ the AC conductivity $\left(\sigma_{\mathrm{AC}}\right)$ and skin depth $(\delta)$ are related to the imaginary permittivity $\left(\varepsilon^{\prime \prime}\right)$, frequency $(\omega)$ and real permeability $\left(\mu^{\prime}\right)$ as $\sigma_{\mathrm{AC}}=\omega \varepsilon_{0} \varepsilon^{\prime \prime},(\sigma=$ $\left.\sigma_{\mathrm{AC}}+\sigma_{\mathrm{DC}}\right)$ and $\delta=\sqrt{2 / \sigma_{\mathrm{AC}} \omega \mu^{\prime}}$, by which we can calculate reflection $\left(\mathrm{SE}_{\mathrm{R}}\right)$ and absorption loss $\left(\mathrm{SE}_{\mathrm{A}}\right)$ as follows:

Reflection loss $\left(\mathrm{SE}_{\mathrm{R}}\right)$ is:

$$
\mathrm{SE}_{\mathrm{R}}(\mathrm{dB})=10 \log \left\{\sigma_{\mathrm{AC}} / 16 \omega \varepsilon_{0} \mu^{\prime}\right\}
$$

and absorption loss $\left(\mathrm{SE}_{\mathrm{A}}\right)$ is

$$
\mathrm{SE}_{\mathrm{A}}(\mathrm{dB})=20\{t / \delta\} \log e=20 d \sqrt{\mu \omega \sigma_{\mathrm{AC}} / 2} \log e=8.68\{t / \delta\}
$$

$$
\mathrm{SE}_{\mathrm{A}}(\mathrm{dB})=8.68 t \sqrt{\sigma \omega \mu^{\prime} / 2}
$$

From eqn (I), it can be deduced that $\mathrm{SE}_{\mathrm{R}}$ is related to frequency $(\omega)$, conductivity $\left(\sigma_{\mathrm{AC}}\right)$ and real permeability while the AC conductivity $\left(\sigma_{\mathrm{AC}}=\omega \varepsilon_{0} \varepsilon^{\prime \prime}\right)$ depends upon the frequency and
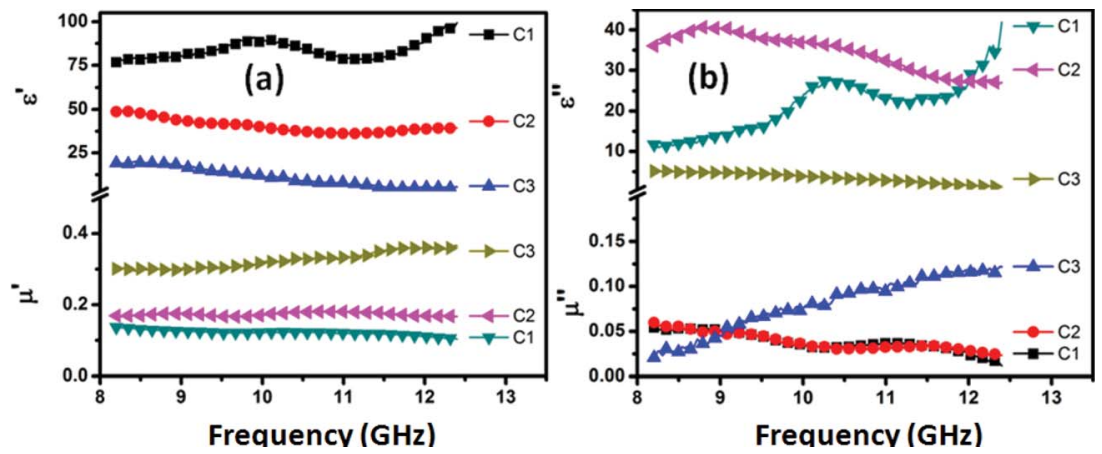

Fig. 4 (a) Real permittivity and permeability $\left(\varepsilon^{\prime}, \mu^{\prime}\right)$, (b) imaginary permittivity and permeability $\left(\varepsilon^{\prime \prime}, \mu^{\prime \prime}\right)$ of CFoams C1, C2 and C3. 
imaginary permittivity $\left(\varepsilon^{\prime \prime}\right)$. As shown in Fig. 4a, the real permeability increases with increasing frequency, and it is at the maximum in the case of CFoam $\mathrm{C} 3$ and at the minimum in C1, while imaginary permittivity (Fig. 4b) also varies with frequency and it is minimum in the case of CFoam C3. This clearly demonstrates that $\mathrm{SE}_{\mathrm{R}}$ is minimum in the case of CFoam C3 and maximum in CFoam C1.

The $\mathrm{SE}_{\mathrm{A}}$ is related to thickness, real permeability, frequency and conductivity. Fig. 4 shows that maximum real permeability is observed in case of $\mathrm{Fe}_{3} \mathrm{O}_{4}-\mathrm{ZnO}$-coated CFoam C3, followed by $\mathrm{C} 2$, and then $\mathrm{CI}$, which has the minimum real permeability, and in all cases the thickness is same.

With a coating of $\mathrm{Fe}_{3} \mathrm{O}_{4}$ and $\mathrm{ZnO}$ nanoparticles on conducting CFoam $\mathrm{C} 1$, electrical conductivity decreases in the case of CFoams C2 and C3, leading to a reduction in the imaginary permittivity. The higher the imaginary component of permittivity, the larger is the loss in the shield material. A material with a low dielectric loss can store energy, but will not dissipate the stored energy. However, a material with a high dielectric loss does not store energy efficiently, and large part of the energy of the incident wave is converted into heat within the shield material. Therefore, materials with lower value of conductivity yield large losses that inhibit the propagation of $\mathrm{EM}$ radiation, i.e., absorption losses are more in the case of CFoam C3. Thus, higher value of real permeability is also responsible for the radiation absorption in CFoam C3. In CFoam, the existence of interfaces between $\mathrm{Fe}_{3} \mathrm{O}_{4}$ nanoparticles-CFoam, $\mathrm{ZnO}$ nanorods-CFoam, and $\mathrm{Fe}_{3} \mathrm{O}_{4}-\mathrm{ZnO}$ are responsible for interfacial polarization, which further contributes to dielectric losses. Interfacial polarization occurs in heterogeneous media due to the accumulation of charges at the interfaces and the formation of large dipoles. Ferromagnetic nanoparticles act as tiny dipoles that are polarized in the presence of EM field and as a result provide better microwave absorption.

The real permeability value of CFoam C3 is more than that of CFoam C2 and C1 (Fig. 4a). This is due to the improvement of magnetic properties along with the parallel reduction of eddy current losses since the coating material has ferromagnetic behaviour. In the microwave range, the natural resonances in the X-band can be attributed to the small size of the $\mathrm{Fe}_{3} \mathrm{O}_{4}$ nanoparticles and $\mathrm{ZnO}$ nanorods in the CFoams. Anisotropy energy of the small size materials, especially at the nanoscale, would be higher due to the surface anisotropic field effect of the smaller material. ${ }^{41}$ The higher anisotropy energy also contributed to the enhancement of microwave absorption. The real and imaginary part of complex permeability increases with frequency in CFoam $\mathrm{C} 3$ and reaches a maximum at a frequency of $12.4 \mathrm{GHz}$, while in CFoams $\mathrm{C} 2$ and $\mathrm{C} 1$, it slightly decrease with frequency (Fig. 4b). This has a positive effect on the absorption of microwave radiation. The magnetic and dielectric coating on the surface of the CFoam (C2 and C3) leads to better matching of input impedance along with a reduction of skin depth. This contributes further to the increase of absorption losses of CFoam. This was confirmed further by measuring saturation magnetization of the CFoam C1, C2 and C3, which is responsible for adsorption losses.

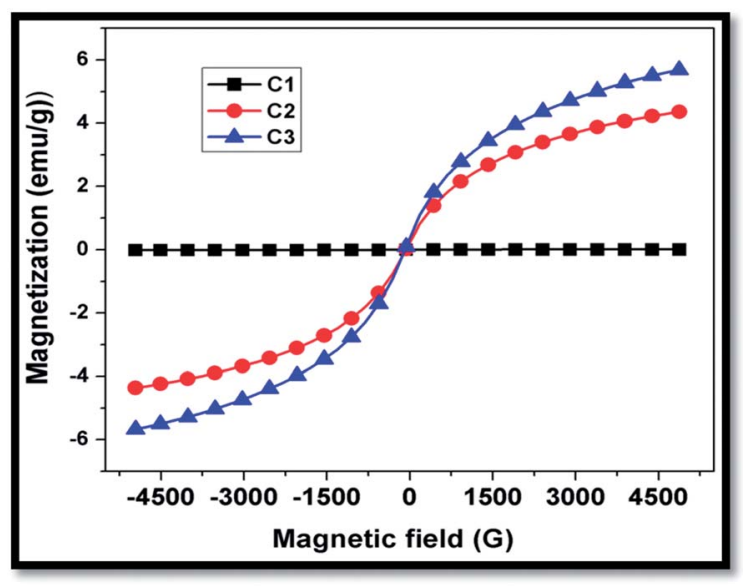

Fig. 5 The room temperature magnetization plot of CFoams C1, C2 and $\mathrm{C} 3$.

\subsection{Magnetic properties of CFoam}

Fig. 5 shows the room temperature magnetization plot of CFoams C1, C2 and C3. The magnetization data reveals that CFoam C1 does not show any magnetization throughout the magnetic field because carbon is nonmagnetic with high electrical conductivity observed because of the delocalized $\pi$ electron. However, $\mathrm{Fe}_{3} \mathrm{O}_{4}$-coated CFoam $\mathrm{C} 2$ and $\mathrm{Fe}_{3} \mathrm{O}_{4}-\mathrm{ZnO}$-coated CFoam $\mathrm{C} 3$ both display a narrow hysteresis loop.

CFoam C2 possesses saturation magnetization $4.2 \mathrm{emu} \mathrm{g}^{-1}$ at $4.9 \mathrm{kG}$, while in CFoam $\mathrm{C} 3$ saturation magnetization is $5.8 \mathrm{emu}^{-1}$. The improved saturation magnetization in the case of CFoam C3 is due to the addition of $\mathrm{ZnO}$ in $\mathrm{Fe}_{3} \mathrm{O}_{4}$, which can also contribute to magnetization. The $\mathrm{ZnO}$ is doped by $\mathrm{Fe}_{3} \mathrm{O}_{4}$ and as a consequence $\mathrm{ZnO}$ becomes ferromagnetic due to the interaction between zinc oxide and ferrous oxide, which form the complex $\mathrm{Zn}-\mathrm{FeO} .^{32,42}$ This can increase the overall magnetic properties of CFoam C3. These results are in agreement with the results of electromagnetic attributes discussed in section 3.4. This clearly demonstrates that even a small uptake of nanoparticle coating on the conducting CFoam is very effective for absorption of radar emission due to its large surface area and its properties.

\subsection{Electromagnetic shielding and microwave absorbing properties}

The microwave shielding can be validated by measuring shielding effectiveness (SE) in terms of reflection and absorption losses. The SE of any shield is the ability to attenuate electromagnetic (EM) radiation that can be expressed in terms of the ratio of incoming (incident) and outgoing (transmitted) power. ${ }^{43}$ The EM attenuation offered by a shield may depend on three mechanisms: reflection of the wave from the front face of shield, absorption of the wave as it passes through the shield and multiple reflections of the waves at various interfaces. ${ }^{\mathbf{4 4}}$ Therefore, $\mathrm{SE}$ is attributed to three types of losses, i.e. reflection loss $\left(\mathrm{SE}_{\mathrm{R}}\right)$, absorption loss $\left(\mathrm{SE}_{\mathrm{A}}\right)$ and multiple reflection losses $\left(\mathrm{SE}_{\mathrm{M}}\right)$, and can be expressed (eqn (IV)) as follows: 


$$
\mathrm{SE}_{\mathrm{T}}(\mathrm{dB})=\mathrm{SE}_{\mathrm{R}}+\mathrm{SE}_{\mathrm{A}}+\mathrm{SE}_{\mathrm{M}}=10 \log \left(P_{\mathrm{t}} / P_{\mathrm{i}}\right)
$$

where $P_{\mathrm{i}}$ and $P_{\mathrm{t}}$ are power of incident and transmitted EM waves, respectively. As $P_{\mathrm{t}}$ is always less than $P_{\mathrm{i}}$; therefore, $\mathrm{SE}$ is a negative quantity such that a shift towards a more negative value means an increase in the magnitude of SE. It is important to note that the losses associated with multiple reflections can be ignored $\left(\mathrm{SE}_{\mathrm{M}} \sim 0\right)$ in all practical cases when achieved $\mathrm{SE}_{\mathrm{T}}$ is more than $-10 \mathrm{~dB}$. Therefore, $\mathrm{SE}_{\mathrm{T}}$ can be expressed as (eqn (V)) follows:

$$
\mathrm{SE}_{\mathrm{T}}(\mathrm{dB})=\mathrm{SE}_{\mathrm{R}}+\mathrm{SE}_{\mathrm{A}}
$$

Fig. 6 shows the EM SE of CFoams C1, C2 and C3 in the Xband (8.2 to $12.4 \mathrm{GHz}$ ) frequency region. It is observed that $\mathrm{SE}_{\mathrm{T}}$ is almost constant throughout the $\mathrm{X}$-band frequency range in all the three types of CFoam, while the reflection component in the form of losses vary with frequency. The SE is the average of 201 data points from 8.2 to $12.4 \mathrm{GHz}$ for the different CFoams. The average value of $\mathrm{SE}_{\mathrm{T}}$ for CFoam $\mathrm{C} 1$ is $-22.3 \mathrm{~dB}$, while in the case of CFoams $\mathrm{C} 2$ and $\mathrm{C} 3$, it increases to -45.7 and $-48.5 \mathrm{~dB}$, respectively. It is interesting to note that in CFoams C2 and C3 the observed $\mathrm{SE}_{\mathrm{T}}$ is more than double that of CFoam $\mathrm{C} 1$. In the case of CFoam $\mathrm{C} 1$, the $\mathrm{SE}_{\mathrm{T}}$ is equally shared by both reflection and absorption losses, while in the case of $\mathrm{Fe}_{3} \mathrm{O}_{4}$ coated CFoam $\mathrm{C} 2, \mathrm{SE}_{\mathrm{T}}$ is governed by absorption losses $(-34.3 \mathrm{~dB})$ and partially shared by reflection losses $\left(\mathrm{SE}_{\mathrm{R}}=11.3 \mathrm{~dB}\right)$. In $\mathrm{Fe}_{3} \mathrm{O}_{4}-$ $\mathrm{ZnO}$-coated CFoam $\mathrm{C} 3$, the presence of $\mathrm{ZnO}$ nanorods along with ferrite nanoparticles further improves the absorption losses $(-41.5 \mathrm{~dB})$, effectively reducing reflection losses $(-7.0 \mathrm{~dB})$ and as a consequence gives the maximum value of $\mathrm{SE}_{\mathrm{T}}(48.5 \mathrm{~dB})$ among the three types of CFoam. Furthermore, CFoam C3 provides higher surface and large interfacial area in comparison to CFoam $\mathrm{C} 2$ and $\mathrm{C} 1$ because of the high aspect ratio of the nanorods, which further enhances the SE due to the absorption. The ZnO nanoparticles not only contribute to the dielectric losses but also to the magnetic losses and as a result the maximum absorption losses were observed in CFoam C3.

In general, the SE increases with increase in conductivity but it is not always true. In our study, electrical conductivity of CFoams C2 and C3 is less than C1, but the SE is double that of C1 (as discussed in the earlier section). This behaviour can be attributed to the incorporation of ferrite particles of lowered complex permittivity $\left(\varepsilon_{\mathrm{r}}\right)$, which improved the equally complex permittivity and permeability $\left(\varepsilon_{\mathrm{r}}\right.$ and $\mu_{\mathrm{r}}$ of the CFoam, which can help in impedance matching. ${ }^{\mathbf{4 1 , 4 5}}$ The specific shielding effectiveness of CFoams C1, C2 and C3 are $-66,-117$ and $-125 \mathrm{~dB} \mathrm{~cm} \mathrm{~cm}^{3} \mathrm{~g}^{-1}$, respectively (Fig. 6d). This is due to the fact that the coatings of $\mathrm{Fe}_{3} \mathrm{O}_{4}$ and $\mathrm{ZnO}$ nanoparticles play an important role in improving magnetic and dielectric losses in the CFoams C2 and C3, which further improves the attenuation of EM radiation.

In Table 2 the available data on the shielding effectiveness of the CFoam is compared. Note that very little information is available in the literature on CFoam as an EMI shield material. From the table, it is very clear that the approach adapted in this study has to date not been applied for improving microwave absorption in CFoam. In most of the reported studies, the total SE is dominated by reflection losses. The reported studies' maximum absorption losses are $25 \%$, while in the present study the absorption losses are more than $80 \%$ of the total SE. Due to the high value of EM absorption by magnetic and dielectric nanoparticles coated CFoam, this can be an excellent material for use in stealth technology.
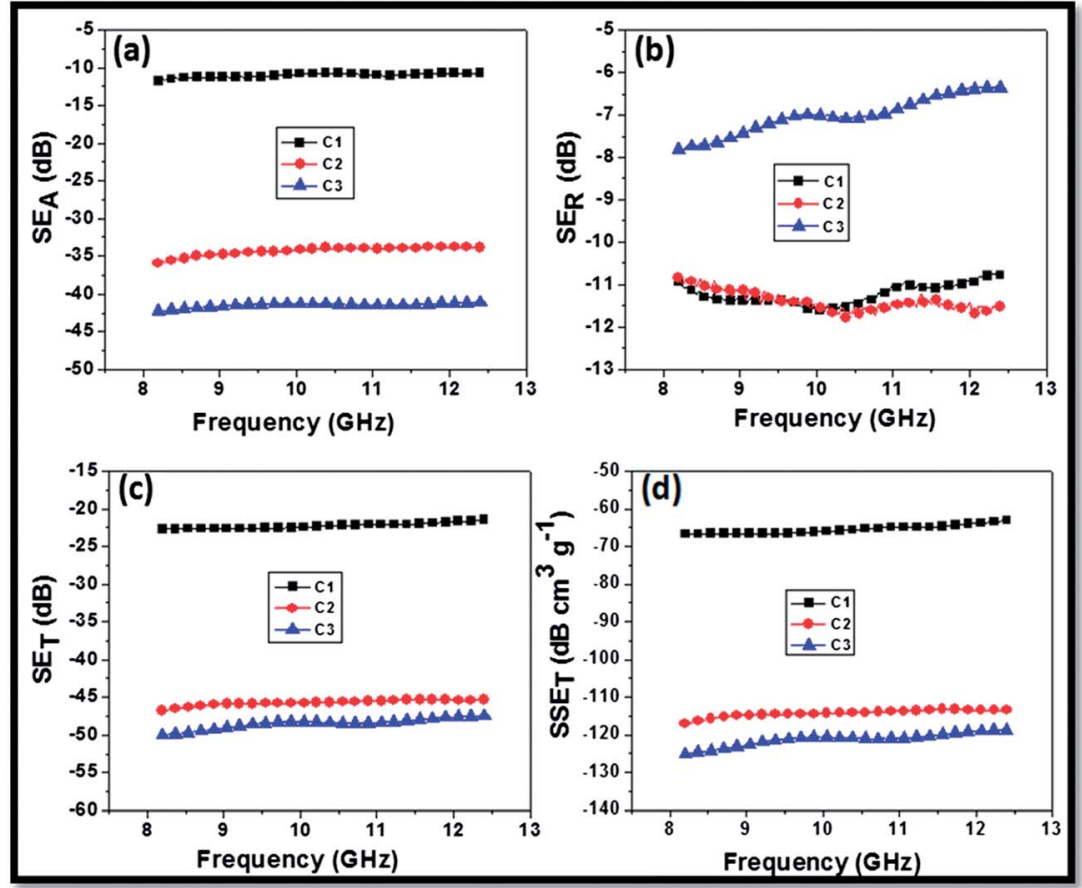

Fig. 6 Electromagnetic shielding effectiveness (a) $\mathrm{SE}_{\mathrm{A}}$ (b) $\mathrm{SE}_{\mathrm{R}}$ (c) $\mathrm{SE}_{\mathrm{T}}$ and (d) specific $\mathrm{SE}_{\mathrm{T}}$ of CFoams C1, C2 and C3. 
Table 2 Comparison of total shielding effectiveness of different CFoam

\begin{tabular}{llllll}
\hline $\begin{array}{l}\text { Carbon foam processing } \\
\text { temp. }\left({ }^{\circ} \mathrm{C}\right)\end{array}$ & $\begin{array}{l}\text { Frequency } \\
\text { range GHz }\end{array}$ & $\begin{array}{l}\text { Thickness of } \\
\text { material }(\mathrm{mm})\end{array}$ & $\begin{array}{l}\text { Total shielding } \\
\text { effectiveness }(\mathrm{dB})\end{array}$ & $\begin{array}{l}\text { Reflection } \\
\text { loss }(\mathrm{dB})\end{array}$ & $\begin{array}{l}\text { Absorption loss } \\
(\mathrm{dB})\end{array}$ \\
\hline $400-800$ & $2-18$ & - & - & 10 & - \\
800 & $8.2-12.4$ & 20 & - & $8-10$ & - \\
Ref.
\end{tabular}

\section{Conclusions}

In summary, lightweight conducting CFoams decorated with magnetic and dielectric nanoparticles have been developed by a simple sacrificial template technique as a radar emission absorbing material. The coatings of magnetic and dielectric particle significantly increase the radar absorption without considerable enhancement in the density of the CFoam. The coating materials can facilitate reducing the number of defects, i.e. cracks on the ligaments, which improve the compressive strength by $100 \%$. The CFoams demonstrate excellent shielding response in the frequency range from 8.2 to $12.4 \mathrm{GHz}$ with absorption dominated total shielding effectiveness value of -47 $\mathrm{dB}(-37 \mathrm{~dB}$ absorption losses $)$ in the case $\mathrm{Fe}_{3} \mathrm{O}_{4}$ coated and -50 $\mathrm{dB}(-41.5 \mathrm{~dB}$ absorption losses $)$ in the case $\mathrm{Fe}_{3} \mathrm{O}_{4}-\mathrm{ZnO}$ coated CFoam. The lightweight CFoams' absorptivity increases due to the decrease in electrical conductivity and increase in dielectric and magnetic losses. Thus, the absorptivity in CFoam increases by $236 \%$ in the $\mathrm{Fe}_{3} \mathrm{O}_{4}$ coated CFoam and $281 \%$ in the $\mathrm{Fe}_{3} \mathrm{O}_{4}-$ ZnO-coated CFoam as compared to the uncoated CFoam. Even though $\mathrm{ZnO}$ is a dielectric material, in the vicinity of iron oxide it will also turn into a somewhat ferromagnetic material after high temperature treatment, which can also contribute to both magnetic and dielectric losses. This study clearly shows that even a small uptake of magnetic and dielectric nanoparticles significantly influences the absorption of EM radiation in conducting CFoams. The lightweight CFoams have absorption losses of $80 \%$ and $20 \%$ reflection losses, thus they can be excellent useful RAMs in stealth technology and in civilian and military applications.

\section{Acknowledgements}

Authors are highly grateful to Director, NPL, for his kind permission to publish the results. Moreover, they are thankful to Mr Jai Tawale and Dr K.N. Sood for the SEM analysis. Rajeev Kumar would like to thank CSIR for the SRF fellowship.

\section{References}

$1 \mathrm{~K}$. Gaylor, Radar Absorbing Materials - Mechanisms and Materials, DSTO Materials Research Laboratory, Cordite Avenue, Maribyrnong, Victoria 3032, Australia, 1989.
2 K. J. Vinoy and R. M. Jha, Radar Absorbing Materials: From theory to Design and Characterization, Kluwer Academic Publishers, Boston, 1996.

3 D. D. L. Chung, J. Mater. Eng. Perform., 2000, 9, 350.

4 D. D. L. Chung, Carbon, 2012, 50, 3342.

5 X. G. Chen, Y. Ye and J. P. Cheng, J. Inorg. Mater., 2011, 26, 449.

6 J. W. Klett, A. D. McMillan, N. C. Gallego and C. A. Walls, Mater. Sci., 2004, 39, 3659.

7 M. Inagaki, T. Morishita, A. Kuno, T. Kito, M. Hirano, T. Suwa and K. Kusakawa, Carbon, 2004, 42, 497.

8 M. Inagaki, New Carbons: Control of Structure and Functions, Elsevier Sci. Ltd, Oxford, 2000.

9 N. C. Gallego and J. W. Klett, Carbon, 2003, 41, 1461.

10 J. W. Klett, A. D. McMillan, N. C. Gallego and C. A. Walls, J. Mater. Sci., 2004, 39, 3659.

11 M. Wang, C. Y. Wang, T. Q. Li and Z. T. Hu, Carbon, 2008, 46, 84.

12 D. Gaies and K. T. Faber, Carbon, 2002, 40, 1137.

13 M. Wang, C. Wang, T. Li and Z. Hu, Carbon, 2008, 46, 84.

14 T. Noda, M. Inagaki and S. Yamada, J. Non-Cryst. Solids, 1969, 1, 285-302.

15 R. D. Klett, US Pat. 3914,392, 1975.

16 J. Klett, R. Hardy, E. Romine, C. Walls and T. Burchell, Carbon, 2000, 38, 953-973.

17 J. W. Klett, A. D. McMillan, N. G. Gallego, T. D. Burchell and C. A. Walls, Carbon, 2004, 42, 1849.

18 R. Kumar, S. R. Dhakate, P. Saini and R. B. Mathur, RSC Adv., 2013, 3, 4145.

19 R. Kumar, S. R. Dhakate, T. Gupta, P. Saini, B. P. Singh and R. B. Mathur, J. Mater. Chem. A, 2013, 1, 5727.

20 J. Yang, Z. M. Shen and Z. B. Hao, Carbon, 2004, 42, 1882-85.

21 Z. Fang, X. CaO, C. Li, H. Zhang, J. Zhang and H. Zhang, Carbon, 2006, 44(15), 3348.

22 Z. Fang, C. Li, J. Sun, H. Zhang and J. Zhang, Carbon, 2007, 45(15), 2873.

23 F. Moglie, D. Micheli, S. Laurenzi, M. Marchetti and V. M. Primiani, Carbon, 2012, 50, 1972.

24 D. Micheli and M. Marcheti, Engineering, 2012, 4, 928.

25 J. M. Blacker and D. J. Merriman, Carbon foam EMI shield, US 0078576A1, 2008.

26 J. M. Blacker and J. W. Plucinski, Electrically graded carbon foam, US 7,867,608 B2, 2011. 
27 P. P. Kuzhir, A. G. Paddubskaya and S. A. Maksimenko, Highly porous conducting carbon foams for electromagnetic applications, International Symposium on Electromagnetic Compatibility (EMC EUROPE), 2012, 978-1-4673-0717-8/12/ $\$ 31.00$ (C) 2012 IEEE.

28 M. Saitoh, T. Yamamoto, T. Sakamoto, H. Niori, M. Chino and M. Kobauashi, Ferroelectrics, 2001, 263, 9.

29 R. Aragón, J. P. Shepherd, J. W. Koenitzer, D. J. Buttrey, R. J. Rasmussen and J. M. Honig, Journal of Applied Physics, 1985, 57, 3221.

30 F. Tuinstra and J. L. Koenig, J. Chem. Phys., 1970, 53, 1126.

31 R. Kumar, S. R. Dhakate and R. B. Mathur, J. Mater. Sci., 2013, 48, 7071.

32 B. Panigrahy, M. Aslam and D. Bahadur, Nanotechnology, 2012, 23, 115601.

33 A. C. Ferrari and J. Robertson, Phys. Rev. B: Condens. Matter Mater. Phys., 2000, 61, 14095.

34 S. R. Dhakate, N. Chauhan, S. Sharma, J. Tawale, S. Singh, P. D. Sahare and R. B. Mathur, Carbon, 2011, 49(6), 1946.

35 O. N. Shebanova and P. Lazor, J. Raman Spectros., 2003, 34, 845.
36 A. M. Nicolson and G. F. Ross, IEEE Trans. Instrum. Meas., 1970, 19, 377.

37 A. P. Singh, P. Garg, F. Alam, K. Singh, R. B. Mathur, R. P. Tandon, A. Chandra and S. K. Dhawan, Carbon, 2012, 50, 3868-3875.

38 J. Wang, H. Zhou, J. Zhuang and Q. Liu, Nat. Sci. Rep., 2013, $3,3252$.

39 N. F. Colaneri and L. W. Shacklette, IEEE Trans. Instrum. Meas., 1992, 41, 29.

40 N. C. Das, D. Das, T. K. Khastgir and A. C. Chakrraborthy, Composites, Part A, 2000, 31, 1069-1081.

41 A. P. Singh, M. Mishra, P. Sambyal, B. K. Gupta, B. P. Singh, A. Chandra and S. K. Dhawan, J. Mater. Chem. A, 2014, 2, 3581.

42 S. Y. Bae, C. W. Na, J. H. Kang and J. Park, J. Phys. Chem. B, 2005, 109, 2526.

43 Y. Yong, M. C. Gupta, K. L. Dudley and R. W. Lawrence, Adv. Mater., 2005, 17, 1999.

44 X. Han and Y. Wang, J. Funct. Mater., 2007, 13, 529.

45 B. Belaabed, J. L. Wojkiewicz, S. Lamouri, N. El Kamchi and T. Lasri, J. Alloys Compd., 2012, 527, 137. 


\title{
Improved microwave absorption in light weight resin based carbon foam by decorating with magnetic and dielectric nanoparticles
}

\author{
R. Kumar, A. P. Singh, M. Chand, R. P. Pant, R. K. Kotnala, S. K. Dhawan, R. B. Mathur, S. R.
} Dhakate*

\author{
CSIR-National Physical Laboratory, \\ Dr. K. S. Krishnan Marg, New Delhi 110012 (India) \\ *Email: dhakate@mail.nplindia.org
}

Figure S1, SEM image of CFoam C2 coated with the ferrofluid and heat treated at $650^{\circ} \mathrm{C}$ in inert atmosphere. It is observed that during heat treatment due to the evaporation of solvent and surfactant, $\mathrm{Fe}_{3} \mathrm{O}_{4}$ nanoparticles are agglomerated and continuous coating is form on the surface of the CFoam ( Figure S1 a). Due to the mismatch of coefficient of thermal expansion between carbon foam and $\mathrm{Fe}_{3} \mathrm{O}_{4}$, the cracks are generated in coating on CFoam shown in Figure $\mathrm{S} 1$ (c).
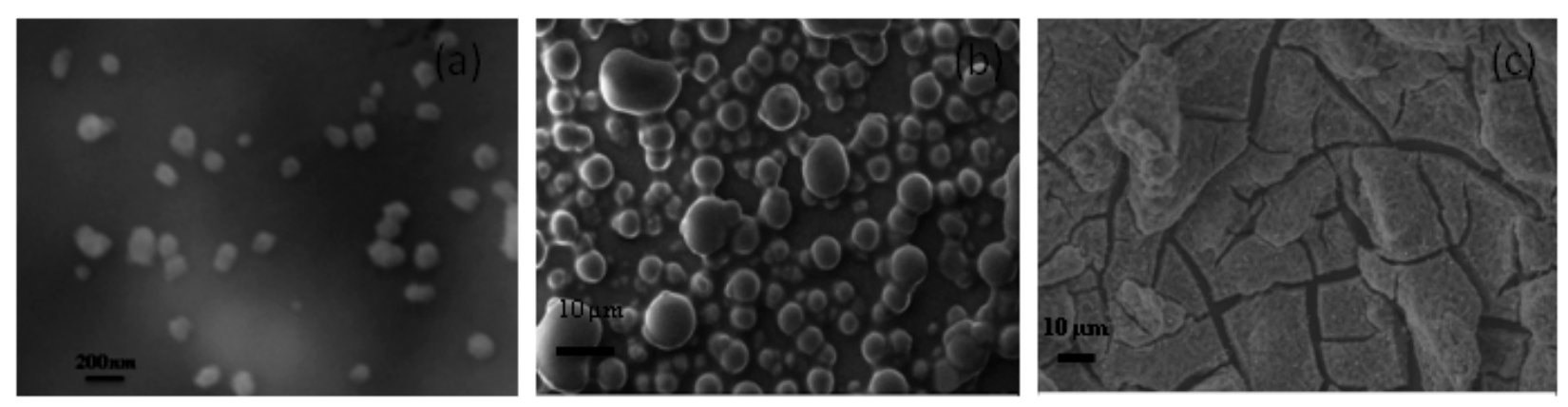

Figure S1 : SEM image of (a) ferrofluid nanoparticles, (b) agglomerated ferrofluid (c) $\mathrm{Fe}_{3} \mathrm{O}_{4}$ coating on CFoam having cracks.

Figure S2 depicted the $\mathrm{ZnO}$ particle synthesized by thermal evaporation of zinc acetate at low temperature $60-70{ }^{\circ} \mathrm{C}$ ( Figure $\mathrm{S} 2 \mathrm{a}$ ). The $\mathrm{ZnO}$ nanoparticles with ferrofluid solution coated on CFoam and heat treated at $650^{\circ} \mathrm{C}$. The $\mathrm{Fe}_{3} \mathrm{O}_{4}$ coated on the mostly on the surface of CFoam while some $\mathrm{Fe}_{3} \mathrm{O}_{4}$ nanoparticles and $\mathrm{ZnO}$ impregnated mostly in the pores of CFoam. After heat 
treatment, it is observed that flower type morphology of $\mathrm{ZnO}$ and $\mathrm{Fe}_{3} \mathrm{O}_{4}$ in the powder form inside the pores ( Figure S2 b, c and d).
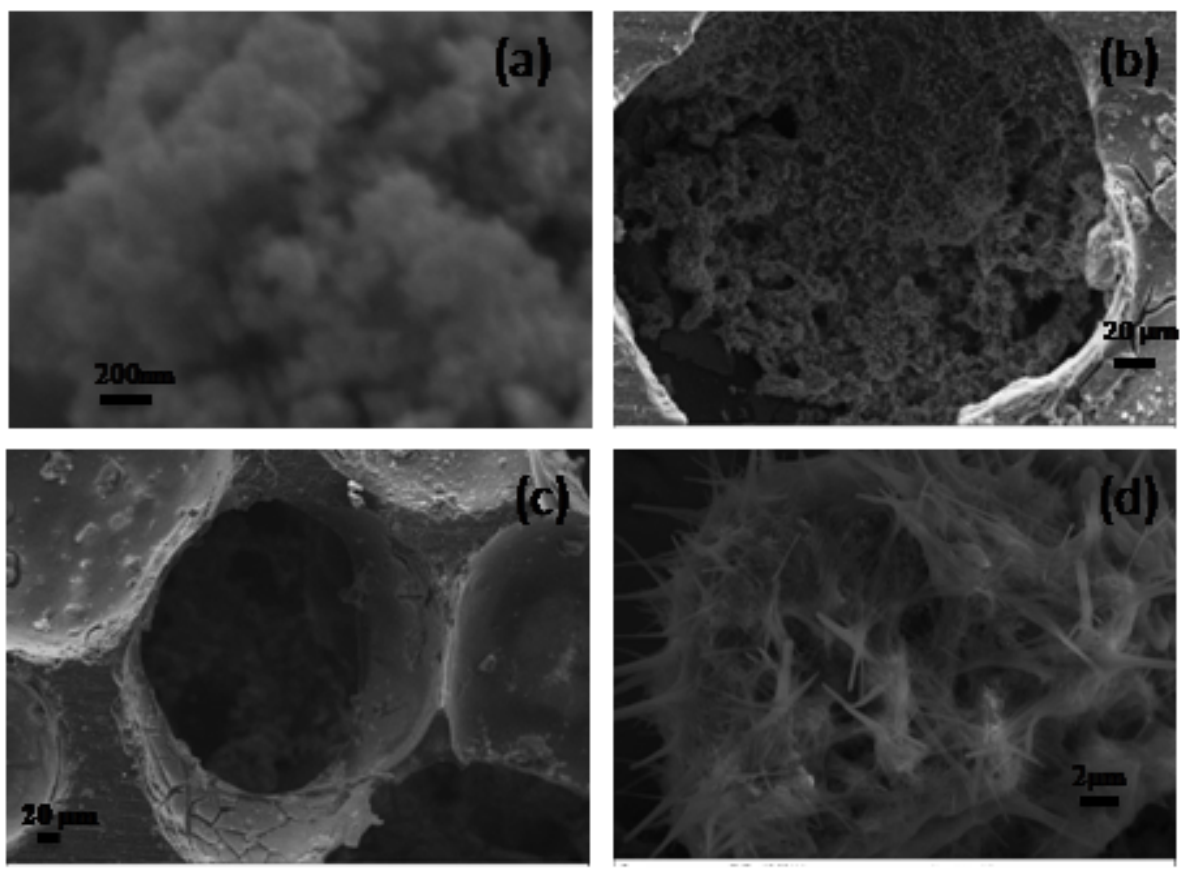

Figure S2: SEM image of ferrofluid and $\mathrm{ZnO}$ nanoparticles synthesized in the laboratory.
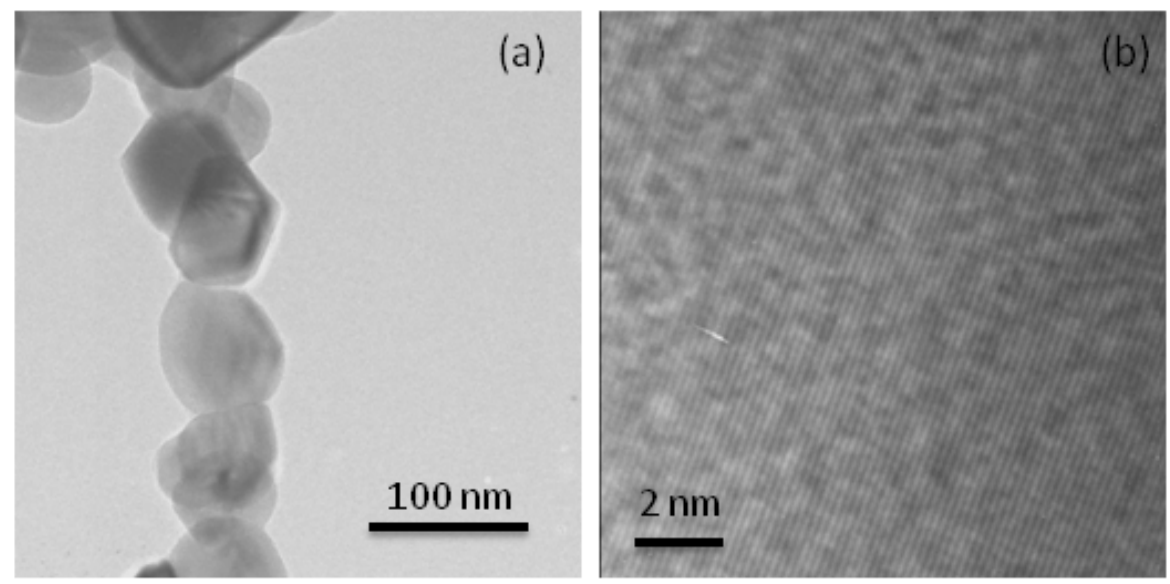

Figure S3: TEM image of $\mathrm{ZnO}$ nanoparticles synthesized by thermal evaporation technique.

Figure S3a is TEM image of $\mathrm{ZnO}$ nanoparticles which are of different shape and size. The particle size is in between $60-70 \mathrm{~nm}$. Figure $\mathrm{S} 3 \mathrm{~b}$ shows the repeated fringes indicate the nonorod type morphology of $\mathrm{ZnO}$ after heat treatment at $650^{\circ} \mathrm{C}$. 
Figure S4 shows the X-ray diffraction spectra of ferrofluid and $\mathrm{ZnO}$. The X-ray diffraction pattern of ferrofluid is characteristic of magnetite $\left(\mathrm{Fe}_{3} \mathrm{O}_{4}\right)$. It is a colloidal suspension of magnetic particles into a carrier liquid by utilizing surfactant to create a colloidal suspension. The surfactants are dispersion agents for particles in a liquid that work by adhering to the particles and creating a net repulsion between them. In particular peaks at $2 \theta$ equal to $30.2,35.6$, 43.2, 53.7, 57.1 and 62.8 (Figure S4 curve a) are index as 220, 311, 400, 511 and 440 lattice planes of cubic magnetite (JCPDS19-629). The peak at 35.66 and 62.8 is due to the Fe-O. Figure $\mathrm{S} 4$ (curve of $\mathrm{ZnO}$ ) is $\mathrm{X}$-diffraction pattern of $\mathrm{ZnO}$. In the spectra peaks at $2 \theta$ equal to $31.8,34.5,36.4,47.6,56.4,62.9,68.0$ are corresponds to $100,002,101,102,110,103,200$ lattice planes of wurtzite $\mathrm{ZnO}$ structure.

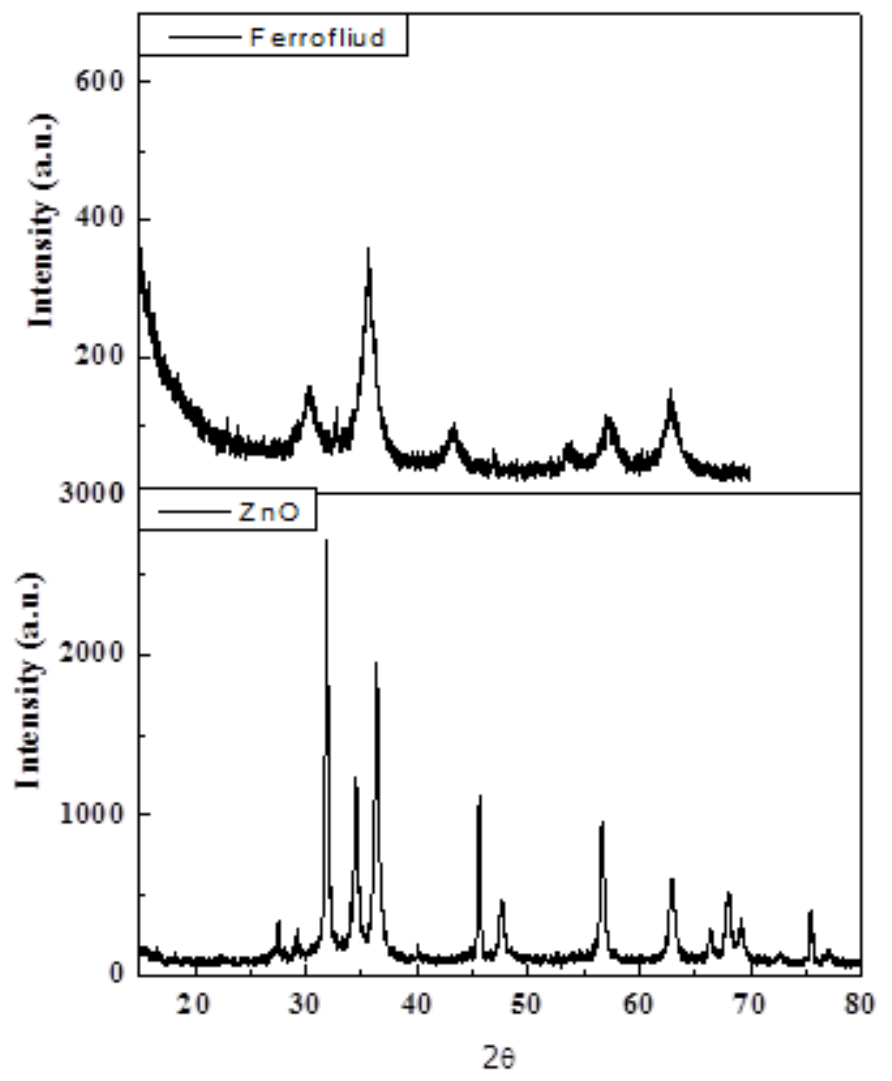

Figure S4: $\mathrm{X}$ ray diffraction pattern of $\mathrm{Fe}_{3} \mathrm{O}_{4}$ and $\mathrm{ZnO}$ nanoparticles. 